\section{Training in Third World Countries: The International Civil Defense Organization (ICDO)}

\section{Dr. Milan Bodi, Secretary General}

The International Civil Defense Organization (ICDO) is helping a large proportion of the Third World Countries where Civil Protection is considered, promoted and organized as a State Service, an obligation of the Authorities toward the population to save it from the devastating effects of a natural or technological disaster or the after-effects of a serious accident. The absence of the industrialized countries within the ICDO has not prevented the poor countries from developing a protection and safety system within the Technical Cooperation Program of ICDO, by their own efforts and with their own resources. The system is based on intervention units, which although sometimes in their embryonic stages, are already capable, however, of administering emergency first aid. Hence the keen interest of those countries in resuscitation techniques.

It is also on behalf of the International Society on Disaster Medicine (ISDM) that I would like to remind the readers of the major concern of the developing countries; certain representatives expressed themselves in this regard in Mainz in 1977 as well as in Monaco in 1979. Allow me to quote some of the statements made by these representatives in Monaco:

Upper Volta. "Thanks to knowledge acquired here, the African doctors, upon return to their countries, can hope to exert pressure on their Governments, whose budget is, however, very restricted, to improve the means which should be applied in case of accident or disaster. Water accident hazards are limited for us, since we have no coastline. However, we are exposed to the bursting of dams during the rainy season. We have very little experience concerning emergency relief means and it is for this reason that we as doctors are interested to the utmost in scientific reports. Often-and this is the tragedy for most countries - the want exceeds the means overwhelmingly, and if we are able to meet the daily needs year in year out, we find ourselves almost without resources in the event of an

From the International Civil Defense Organization, 10-12 Chemin de Surville, 1213 Petit-Lancy, Geneva, Switzerland. (Telephone: $22-334433$.) accident. Considering that one anaesthetist alone in the Ivory Coast has the task of training all the others, that $50 \%$ of the doctors in Upper Volta are concentrated in the cities, whereas the problems in the rural areas are enormous, it is understandable to what extent the measures discussed at this conference seem to come out of a dream for the African representatives."

Ivory Coast. "It is our wish to speak about intervention, the measures to be taken, equipment and new techniques, for even if we have the theory, we lack practice."

Gabon. "We expect much from the conference with respect to training. We want to convince our Governments of the necessity of forming cadres. The conference will have given us weighty arguments. Even if the scientific level of these meetings has been extremely valuable to us, we are aware that the experiences of advanced countries are inapplicable in our own. Yet we experience more disasters than in Europe or the United States. We would wish to be aided in resolving these problems and assisted in the training of relief personnel. Moreover, since we do not have a large infrastructure, it is important that our medicine emphasize its efforts in prevention."

We would urge specialists to consider primary resuscitation care adapted to conditions of the poor countries. Medical students, soon in excess in the industrialized countries, could be usefully directed towards mass medicine or to elementary emergency medicine, which is sorely lacking in most of the developing countries. Also, more chairs of disaster medicine could be established in European universities to train foreign students in this field.

The conclusion of the "Declaration of Alma-Ata," adopted by the International Conference on Primary Health Care, organized jointly in 1978 by the World Health Organization and the United Nation's Children's Fund include: "The International Conference on Primary Health Care calls for urgent and effective national and international action to develop and implement primary health care throughout the world-and in keeping with a New International Economic Order. It urges governments, WHO and UNICEF, and other international organizations, as well as multilateral and bilateral agencies, non-governmental organizations, funding agencies, all health workers and the whole world community to support national and international commitments to primary health care and to channel increased technical and financial support to it, particularly in developing countries. The Conference calls upon all to collaborate in introducing, developing and maintaining primary health care in accordance with the spirit and content of this Declaration. 